\title{
Transcatheter aortic valve insertion in the nonagenarian patient
}

\author{
Kevin L. Greason, MD, ${ }^{a}$ Alberto Pochettino, MD, ${ }^{a}$ Gurpreet S. Sandhu, MD, PhD, ${ }^{b}$ and \\ Verghese Mathew, MD, ${ }^{\mathrm{b}}$ Rochester, Minn
}

See related commentaries on pages 721-3 and 723-4.

There are reports detailing conflicting outcomes of aortic valve replacement in nonagenarian patients, with some studies noting a high observed-to-expect mortality ratio. ${ }^{1,2} \mathrm{We}$ hypothesized that transcatheter valve insertion would result in low operative mortality and reasonable long-term survival in this extremely elderly cohort of patients.

\section{MATERIALS AND METHODS}

The Mayo Clinic's institutional review board approved this study. We reviewed the records of 398 patients operated on with transcatheter aortic valve insertion from November 2008 through June 2014.

Data were recorded according to the standard definitions set forth in the Society of Thoracic Surgeons Adult Cardiac Database and the Valve Academic Research Consortium-2 (VARC-2) consortium document. ${ }^{3}$ Frailty was assessed on the basis of the 5-meter walk test, hand grip, serum albumin level, and the Katz Index of Independence in Activities of Daily Living; patients were considered frail if they failed to meet 3 out of 4 of the criteria.

Categoric data were reported as patient numbers with percentages, and continuous data were reported as median and range. Data were analyzed with the Fisher exact test, the Wilcoxon nonparametric rank test, and Kaplan-Meier estimates. The expected survival probabilities for the group of individuals matched on age, calendar year, and sex was based on a set of tables containing published survival probabilities for the US population, by interpolation between decades changing hazard values on each birthday.

From the group of 398 patients, a study cohort was created that included 46 nonagenarian patients $(11.6 \%)$ with a median age of 91.5 years $(90$ 95 years), 28 female patients $(60.9 \%)$, and a median Society of Thoracic Surgeons predicted risk of mortality of $8.5 \%(4.0 \%-27.9 \%)$. Additional risk variables are reported in Table 1.

\section{RESULTS}

Transcatheter access was transfemoral in 24 patients $(52.2 \%)$, transapical in $19(41.3 \%)$, and transaortic in 3 $(6.5 \%)$. Valve types included the SAPIEN valve (Edwards Lifesciences Corporation, Irvine, Calif) in 32 patients $(69.6 \%)$, the SAPIEN XT in $6(13.0 \%)$, the SAPIEN S3 in $7(15.2 \%)$, and the CoreValve (Medtronic, Minneapolis, Minn) in $1(2.2 \%)$.

From the ${ }^{\mathrm{a} D i v i s i o n}$ of Cardiovascular Surgery, Mayo Clinic, Rochester, Minn; and the ${ }^{\mathrm{b}}$ Division of Cardiovascular Diseases, Mayo Clinic, Rochester, Minn.

Disclosures: Authors have nothing to disclose with regard to commercial support.

Received for publication March 9, 2015; revisions received April 21, 2015; accepted for publication April 27, 2015

Address for reprints: Kevin L. Greason, MD, Division of Cardiovascular Surgery, Mayo Clinic, 200 First St SW, Rochester, MN 55905 (E-mail: greason.kevin@ mayo.edu).

J Thorac Cardiovasc Surg 2015;150:720-1

0022-5223/\$36.00

Copyright (c) 2015 by The American Association for Thoracic Surgery

http://dx.doi.org/10.1016/j.jtcvs.2015.04.055
TABLE 1. Baseline patient risk characteristics

\begin{tabular}{lc}
\hline Ejection fraction (median and range) & $0.64(0.25-0.80)$ \\
Ejection fraction $\leq 50 \%$ & $12(26 \%)$ \\
Diabetes & $11(23.9 \%)$ \\
Hypertension & $40(87.0 \%)$ \\
Chronic lung disease & $19(41.3 \%)$ \\
Peripheral vascular disease & $26(56.5 \%)$ \\
Cerebrovascular disease & $17(37.0 \%)$ \\
$\quad$ Previous stroke & $9(19.6 \%)$ \\
Previous cardiac operation & $17(37.0 \%)$ \\
Arrhythmia & $13(28.3 \%)$ \\
New York Heart Association functional class III or IV & $40(87.0 \%)$ \\
Mitral valve regurgitation moderate or greater & $17(37.0 \%)$ \\
Frailty, objective & $4 / 14(28.6 \%)$ \\
Domicile & \\
$\quad$ Minnesota or bordering state & $40(87.0 \%)$ \\
$\quad$ Nonbordering state & $6(13.0 \%)$ \\
\hline Data represent numbers and percentages of patients except as noted.
\end{tabular}

Operative complications occurred in 22 patients $(47.8 \%)$ and included prolonged ventilation in 3 patients $(6.5 \%)$, permanent pacemaker placement in $3(6.5 \%)$, stroke in 1 $(2.2 \%)$, and dialysis in $1(2.2 \%)$. Vascular injury occurred in 10 patients, and only in the transfemoral access group $(45.5 \%)$ - the valve was a SAPIEN valve in 8 patients $(25.0 \% ; 7$ major and 1 minor according to VARC-2 criteria) and SAPIEN S3 in 2 (28.6\%; both minor according to VARC-2 criteria).

There were 2 treatment-related deaths $(4.7 \%), 1$ from stroke and 1 from multisystem organ failure. The observed-to-expected mortality ratio was 0.55 . The median length of stay was 5 days (1-21) and did not differ according to vascular access method $(P=.333)$. Discharge was to home in 18 cases $(40.9 \%)$ and to a skilled nursing facility in $26(59.1 \%)$.

Survival at 1 and 2 years was $84.6 \% \pm 10.6 \%$, and these data were similar to an age- and sex-matched control population, as reported in Figure $1(P=.286)$. Median follow-up was 17.3 months (0-61.4 months), at which time 35 patients $(76.1 \%)$ were alive. There was no difference in survival according to access method $(P=.438)$ or discharge disposition $(P=.497)$.

\section{DISCUSSION}

This study reports our experience with transcatheter aortic valve insertion in nonagenarian patients. Despite high predicted operative risk, outcomes were excellent with low operative stroke $(2.2 \%)$ and death $(4.7 \%)$ rates (observed-to-expected ratio 0.55). Follow-up through 2 years demonstrates survival similar to that of an age- 


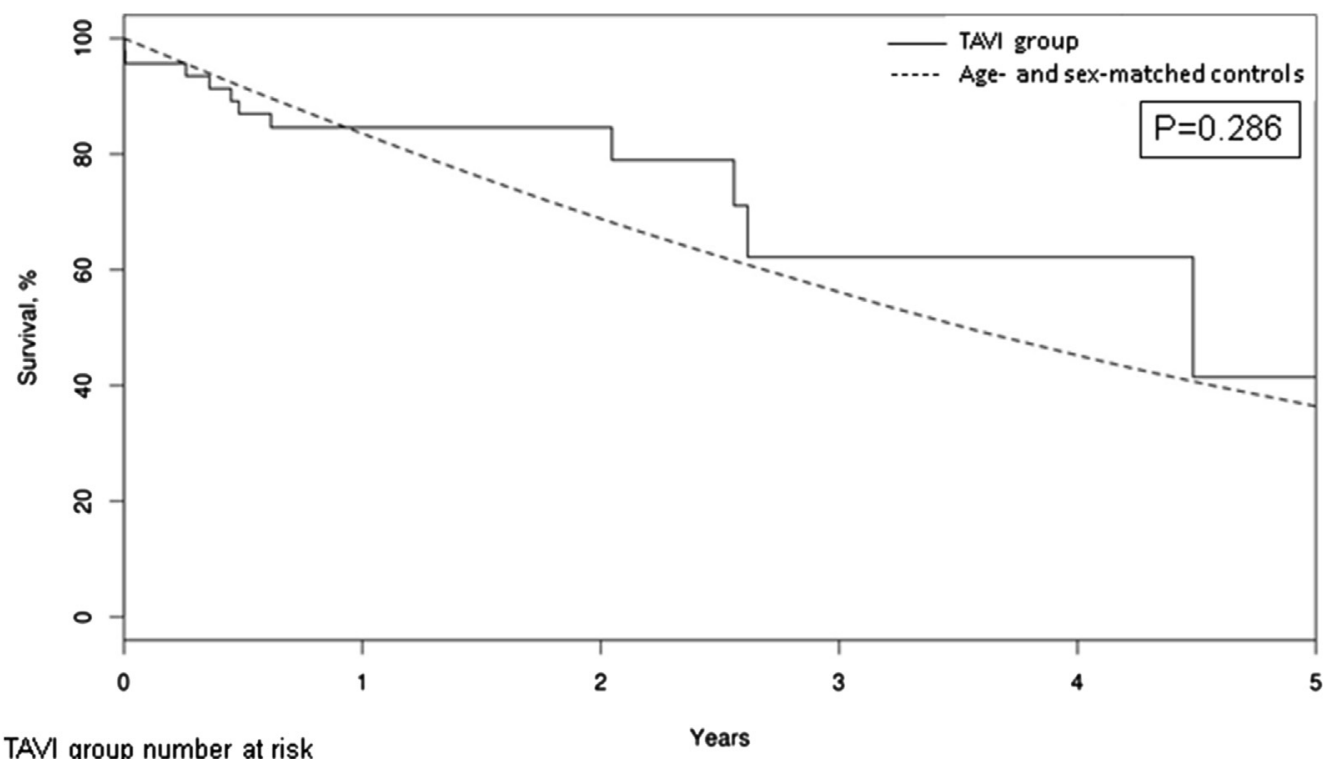

TAVI group number at risk

46

30

15

7

5

1

FIGURE 1. Kaplan-Meier survival estimates of patients after transcatheter aortic valve insertion compared with an age- and sex-matched control population. TAVI, Transcatheter aortic valve implantation.

and sex-matched control population. Transcatheter valve replacement should not be denied to select patients.

\section{References}

1. Davis JP, LaPar DJ, Crosby IK, Kern JA, Lau CL, Kron IL, et al. Nonagenarians undergoing cardiac surgery. J Card Surg. 2014;29:600-4.
2. Murashita T, Greason KL, Suri RM, Nkomo VT, Holmes DR, Rihal CS, et al. Aortic valve replacement for severe aortic valve stenosis in the nonagenarian patient. Ann Thorac Surg. 2014;98:1593-7.

3. Kappetein AP, Head SJ, Généreux P, Piazza N, van Mieghem NM, Blackstone EH, et al. Updated standardized endpoint definitions for transcatheter aortic valve im plantation: the Valve Academic Research Consortium-2 consensus document. $J$ Thorac Cardiovasc Surg. 2013;145:6-23.

\section{EDITORIAL COMMENTARY}

\section{Pushing the limits or the new normal? Transcatheter aortic valve replacement in nonagenarians}

Torsten P. Vahl, MD, PhD, ${ }^{a}$ and Michael A. Borger, $\mathrm{MD}, \mathrm{PhD}^{\mathrm{b}}$

See related article on pages 720-1.

From the ${ }^{\mathrm{a}} \mathrm{Heart}$ Valve Center and ${ }^{\mathrm{b}}$ Division of Cardiac, Thoracic, and Vascular Surgery, Columbia University Medical Center, New York, NY.

Disclosures: Authors have nothing to disclose with regard to commercial support.

Received for publication May 28, 2015; accepted for publication June 3, 2015; available ahead of print July 3, 2015.

Address for reprints: Michael A. Borger, MD, PhD, Division of Cardiac, Thoracic and Vascular Surgery, Columbia University Medical Center, 177 Fort Washington Ave, MHB 7GN-435, New York, NY 10032 (E-mail: mb3851@ cumc.columbia.edu). J Thorac Cardiovasc Surg 2015;150:721-3

$0022-5223 / \$ 36.00$

Copyright $\odot 2015$ by The American Association for Thoracic Surgery http://dx.doi.org/10.1016/j.jtcvs.2015.06.008
With a continuously aging population and an increased prevalence of severe aortic stenosis in the elderly, both surgeons and cardiologists are more frequently confronted with treatment decisions in a very complex patient population. By the year 2050, estimates indicate that the number of nonagenarians in the United States will increase from 2 to 8 million (Figure 1). ${ }^{1}$ Advanced age is a key component in preoperative patient evaluation and risk estimation for patients undergoing surgical aortic valve replacement (SAVR). For patients aged $>90$ years in particular, surgical risk has been traditionally perceived as excessive, and many patients of this age were therefore not referred for SAVR by their physicians. Surgical 